\title{
A pandemia da Covid-19 e seus impactos no setor cultural brasileiro
}

\section{The COVID-19 pandemic and its impacts on the Brazilian cultural sector}

\section{La pandemia COVID-19 y sus impactos en el sector cultural brasileño}

\author{
iD Mariana de Araujo Aguiar \\ Universidade Federal do Rio de Janeiro, Rio de Janeiro, Rio de Janeiro, Brasil \\ m.arauguiar@gmail.com
}

iD (9) Luciana de Araujo Aguiar

Université Paul-Valery - Montpellier III, Montpellier, Occitanie, França aguiar_luciana@hotmail.com

Resumo: Este artigo tem como objetivos descrever e examinar a virtualização do setor cultural brasileiro durante a pandemia da Covid-19; analisar as respostas do governo brasileiro face à crise do setor e identificar as percepções de artistas fluminenses sobre os impactos socioeconômicos da pandemia. A metodologia usada para atingir esses objetivos inclui pesquisa documental e coleta de dados através de um questionário. A abordagem teórica centra-se nos conceitos de virtualização e direitos culturais. Os resultados da pesquisa mostram que um grande número de artistas começou a usar ferramentas online para continuar suas atividades profissionais. No entanto, apesar de algumas vantagens, a impossibilidade de rentabilizar as produções e a consequente perda econômica são colocadas como grandes desvantagens dessa virtualização. No que tange às políticas culturais, o aspecto que se tornou mais evidente, nas respostas adquiridas, refere-se ao modelo de gestão e sua ineficácia.

Palavras-chaves: Cultura. Covid-19. Brasil. Política Pública. Virtualização. 
Abstract: This paper aims to describe and examine the virtualization of the Brazilian cultural sector during the COVID-19 pandemic; analyze the Brazilian government's response to the sector's crisis and identify the perceptions of the Rio de Janeiro artists about the socioeconomic impacts of the pandemic. The methodology used to achieve these objectives includes documentary research and data collection through a questionnaire. The theoretical approach focuses on the concepts of virtualization and cultural rights. The results of the survey show that a large number of artists have begun to use online tools to continue their professional activities. However, despite some advantages, the impossibility of making the productions profitable and the consequent economic loss are placed as major disadvantages of this virtualization. As far as cultural policies are concerned, the aspect that became most evident in the responses acquired refers to the management model and its its ineffectiveness

Keywords: Culture. COVID-19. Brazil. Public Policy. Virtualization.

Resumen: Este artículo pretende describir y examinar la virtualización del sector cultural brasileño durante la pandemia de COVID-19; analizar la respuesta del gobierno brasileño a la crisis del sector; e identificar las percepciones de los artistas de Río de Janeiro sobre los impactos socioeconómicos de la pandemia. La metodología utilizada para alcanzar estos objetivos incluye la investigación documental y la recogida de datos mediante un cuestionario. El enfoque teórico se centra en los conceptos de virtualización y derechos culturales. Los resultados de la encuesta muestran que un gran número de artistas han empezado a utilizar herramientas en línea para continuar con sus actividades profesionales. Sin embargo, a pesar de algunas ventajas, la imposibilidad de rentabilizar las producciones y la consiguiente pérdida económica se sitúan como grandes desventajas de esta virtualización. En cuanto a las políticas culturales, el aspecto que se hizo más evidente en las respuestas adquiridas se refiere al modelo de gestión y su inoperância.

Palabras clave: Cultura. COVID-19. Brasil. Política pública. Virtualización.

Data de recebimento: $20 / 10 / 2020$

Data de aprovação: 10/02/2021 


\section{Introdução}

A pandemia da Covid-19 alterou nossas rotinas e impactou a sociedade. O mundo, tal como conhecíamos, desacelerou. A primeira lição do novo coronavírus, como menciona Bruno Latour (2020), foi provar que é possível, em questão de semanas, suspender um sistema econômico que até agora nos diziam ser impossível desacelerar ou redirecionar. Entre as várias mudanças com que estamos sendo confrontados, nos chamam particularmente atenção a virtualização do setor cultural e o consumo digital da cultura. Para lidar com a restrição da aglomeração de público, vimos multiplicar as lives, transmissões ao vivo de áudio e vídeo na internet, em plataformas digitais. O coronavírus fez explodir o mundo virtual e fez também irromper as desigualdades do acesso ao digital.

Segundo dados da revista Exame, houve um crescimento de 20\% na audiência de sites de streaming em março de 2020, em grande parte devido aos países das Américas (AGRELA; CURY; VITORIO, 2020) e, além disso, as buscas por conteúdo ao vivo aumentaram $4.900 \%$ no Brasil durante os dois primeiros meses da quarentena, representando uma audiência 20 vezes maior que a dos vídeos gravados, segundo o mesmo relatório. No entanto, os produtores nem sempre conseguem monetizar suas obras. Em relação às transmissões ao vivo, por exemplo, que são em sua maioria gratuitas, constatamos que algumas são patrocinadas por empresas que divulgam suas marcas durante o evento, o que ajuda a gerar renda para os artistas. Um grande número de músicos e artistas independentes, entretanto, não se beneficia desses patrocínios, revelando as disparidades econômicas na indústria cultural.

Além disso, o uso de plataformas digitais no Brasil ainda não é compartilhado por toda a população. Segundo dados publicados no Sistema de Indicadores e Informações Culturais (IBGE, 2019), em 2018, 14,8\% da população brasileira vivia em municípios sem provedor de acesso à internet. Portanto, como aponta Boaventura 
de Souza Santos (2020), a pandemia não é democrática e tem alvos privilegiados. Os efeitos, para grupos sociais mais vulneráveis, vão além do pânico em se isolar e expressam a falência das sociedades em não garantir os direitos fundamentais dos seres humanos ${ }^{1}$, como, por exemplo, o direito à cultura que, de acordo com a Constituição Federal (CF) de 1988, se insere na perspectiva dos direitos sociais fundamentais, como exposto no artigo 215: “O Estado garantirá a todos o pleno exercício dos direitos culturais e acesso às fontes da cultura nacional, e apoiará e incentivará a valorização e a difusão das manifestações culturais." (BRASIL, 1988).

Tendo como ponto de partida esses aspectos, o artigo tem como objetivo: 1 - descrever e examinar a virtualização do setor cultural brasileiro durante a pandemia da Covid-19; 2 - analisar as respostas do governo brasileiro face à pandemia, e perante o setor cultural; e 3 - identificar as percepções de artistas fluminenses sobre os impactos socioeconômicos da pandemia e sobre as respostas do governo. Para isso, o artigo foi dividido em três partes, além desta introdução e as considerações finais. A metodologia usada para atingir esses objetivos inclui pesquisa documental, a partir da análise de conteúdo de reportagens e documentos legislativos, e coleta de dados através de um questionário enviado a artistas residentes no estado do Rio de Janeiro. A abordagem teórica centra-se nos conceitos de virtualização, Estado e cultura e economia da cultura.

\section{A virtualização do setor cultural durante a pandemia da Covid-19}

Desde março de 2020, músicos e cantores dos mais diversos estilos musicais usaram as transmissões ao vivo em plataformas digitais para apresentar seus trabalhos. Alguns deles utilizam o

\footnotetext{
1 Os direitos fundamentais são "normas constitucionais de caráter principiológico, que visam proteger diretamente a dignidade humana nas suas diferentes manifestações" (LOPES, 2008, p. 24). Assim, a proteção da dignidade humana e a salvaguarda do bem-estar ocorrem de forma direta e sem mediações normativas.
} 
A pandemia da Covid-19 e seus impactos no setor cultural brasileiro

Mariana de Araujo Aguiar • Luciana de Araujo Aguiar

celular para as transmissões. Classificado como "caseiro", esse formato conta com poucos equipamentos de áudio e vídeo e possui durações mais curtas. Outras podem ser classificadas como "super-lives". De acordo com Lucas Brêda (2020), a live do cantor sertanejo Gusttavo Lima, chamada de "Buteco em Casa", exibida no fim de março de 2020 e filmada até por um drone, foi um marco desse formato. As lives podem ser transmitidas por músicos e grupos musicais de forma individual, ou podem fazer parte de festivais de música, agrupando músicos de estilos e ritmos diferentes. Entre estes festivais podemos citar: Festival \#tamojunto, Festival Música em Casa, Festival Fico em Casa BR, GE Festival, Folk no Sofá, Festival na Sala e Festival Lá de Casa (RAMOS, 2020).

As lives produzem um tipo de sociabilidade diferente daquela do mundo "físico": enquanto assistem ao mesmo show, amigos trocam mensagens em aplicativos de conversa e, além disso, pode-se acompanhar o que os outros internautas comentam instantaneamente. Isso provoca sentimentos de cumplicidade e de vínculos de comunhão, o que não ocorre em shows gravados disponíveis em plataformas como YouTube. O usuário, portanto, se sente parte presente do show, e não apenas espectador. As lives promovidas pela sambista carioca Teresa Cristina se tornaram um exemplo evidente desse formato de sociabilidade.

Não só músicos e cantores adotaram as lives como ferramentas para expor, divulgar e apresentar seus trabalhos, mas diversos outros artistas também o fizeram. Há lives de leitura de peças dramatizadas, contação de histórias, serestas e encontros literários, apresentações performáticas etc. Para além das transmissões ao vivo, outra forma de apresentar e tornar acessíveis os trabalhos artísticos por meio virtual é o streaming gravado. ${ }^{2}$ Atores e atrizes com peças de teatro gravadas estrearam virtualmente e se mantêm em temporada online. Além das temporadas, plataformas digitais colaborativas que promovem o acesso gratuito do público às artes cênicas por streaming foram criadas, como é o caso do site

2 Streaming é uma forma de distribuição digital de vídeo em que não há armazenamento de dados pelo usuário em seu computador, ou seja, não há download, assim não é ocupado espaço no disco rígido (HD). 
Espetáculos Online. ${ }^{3}$ No âmbito do cinema, festivais e instituições culturais exibiram mostras online de filmes, assim como algumas produtoras, que disponibilizaram uma lista especial de filmes para serem assistidos como, onde e quando o usuário desejar.

Instituições culturais do mundo inteiro mobilizaram recursos digitais e virtuais para a exibição das expressões, formas e elementos culturais e artísticos durante a pandemia. A virtualização do setor cultural é um dos aspectos mais remarcáveis durante a pandemia da Covid-19. Entre os autores que se dedicaram ao estudo do conceito de virtual e virtualização, podemos citar o filósofo Pierre Lévy (1996). Para este autor:

O virtual está constituído em estado latente, pronto a se transformar no real, por exemplo, a semente de uma árvore. A árvore está na semente, mas no atual momento não está aparecendo, mas nem por isso deixa de ser real. O virtual não é algo pronto e estático, é considerado como um nó de tendências, de força e potência [...] é como a passagem do possível para o real, ampliando espaços e tempos. (LÉVY, 1996, p. 17).

Para Lévy (1996), a virtualização se opõe à atualização e não ao real. A partir dessa compreensão, o autor destrincha alguns aspectos da virtualização, entre eles, podemos citar a não presença, no sentido espacial e temporal. No entanto, o autor destaca que o virtual implica em processos de acolhimento e alteridade, portanto, as comunidades virtuais são imbuídas de paixões, conflitos, amizades etc.

Outro aspecto presente na produção de Lévy (1999) é a noção de cibercultura. Esta se refere ao "conjunto de técnicas (materiais e intelectuais), de práticas, de atitudes, de modos de pensamento e de valores que se desenvolvem juntamente com o crescimento do ciberespaço" (LÉVY, 1999, p. 17). De acordo com o autor, para a cibercultura, a conexão é sempre preferível ao isolamento. Isso al-

3Cf.: https://espetaculosonline.com 
A pandemia da Covid-19 e seus impactos no setor cultural brasileiro Mariana de Araujo Aguiar • Luciana de Araujo Aguiar

tera a física da comunicação, que passa a adotar uma perspectiva de espaço envolvente e possibilita a construção de comunidades virtuais. Ao tratar sobre as artes do virtual, Lévy (1999) define o conceito de ciberarte a partir de alguns traços gerais, como, por exemplo: a criação coletiva, a criação contínua e a interatividade.

A contribuição teórica de Lévy é de extrema importância para entendermos aspectos evidentes na produção cultural virtual, no entanto, sua visão otimista e inebriante encobre aspectos críticos da cibercultura, como, por exemplo, a dependência da cibercultura à dinâmica do capitalismo (SIEGEL, 2008 apud RÜDIGER, 2011) movido pelo poder econômico das grandes empresas (Google, Facebook e outras) que promove um "processo massificado de abstração da própria escolha individual" (RÜDIGER, 2011, p. 56).

Para além desse aspecto, Siegel (2008 apud RÜDIGER, 2011) ressalta que a cibercultura se alimenta de uma suposta democracia e coletividade, no entanto, é a expressão individual que move a cibercultura, ou seja, a forma de se apresentar como indivíduo e o desejo individual de se sentir aceito que promove a ampla audiência das redes sociais, por exemplo. Outras problemáticas associadas à cibercultura também foram abordadas por diversos autores, como: a ameaça ao sentimento de pertencimento a um lugar, a privação dos sentimentos de responsabilidade e o abandono das preocupações com a realidade física (SLOUKA, 1995 apud RÜDIGER, 2011).

David Harvey (2020) levanta a questão sobre a maneira como o setor cultural é consumido. O autor nomeia como "economia Netflix" o novo consumo virtual da cultura. ${ }^{4}$ No entanto, se este novo modo de consumo contempla o que Harvey (2020) chama de "espectadores compulsivos", atraindo uma grande quantidade de público, a renda gerada é apropriada de forma desigual. A maioria das lives, por exemplo, produzidas por músicos, cantores e grupos musicais são gratuitas. Entre as poucas formas de financiamento das lives podemos citar os anúncios em plataformas como o

4 Plataforma paga de visualização de vídeos por streaming, a Netflix se destaca no mercado internacional pela produção e difusão de filmes e séries de televisão. 
YouTube, que permitem gerar receita para os donos dos canais; o patrocínio de algumas marcas; o pagamento pelos fãs de lives privadas por meio de depósito bancário em plataformas tais como o Zoom, ${ }^{5}$ e o financiamento por empresas privadas ou instituições do Sistema S, como é o caso do SESC/SP. Esses financiamentos, no entanto, estão ainda muito aquém dos ganhos com os shows e, além disso, outros profissionais técnicos continuam sem renda. Para tentar contornar essa anunciada crise, empresas e startups têm buscado soluções para gerenciar, distribuir e monetizar vídeos e conteúdos digitais. ${ }^{6}$

Portanto, o contexto do distanciamento social provocado pela pandemia exacerbou o impacto das tecnologias digitais nas dinâmicas econômicas globais. Lessing (2009) aponta que as tecnologias digitais alteraram as formas de produção, acesso e consumo dos bens. $O$ autor destaca que, além da economia comercial, baseada na relação produto/dinheiro, houve o advento da economia do compartilhamento, baseada no compartilhamento de conteúdo que sustenta o Wikipedia, por exemplo; e o modelo de economia híbrida, que é aquela que utiliza o compartilhamento para fins comerciais como o Uber, Airbnb e, no ramo da cultura, podemos citar as empresas de streaming, YouTube e outros.

\section{O Estado brasileiro frente às mudanças do setor cultural}

Desde maio de 2020 a América Latina e Caribe tornaram-se a região mais afetada pelo novo coronavírus. Alguns aspectos podem explicar o alto grau de contágio. A Comissão Econômica para América Latina e Caribe (CEPAL) aponta que a maioria dos países latino-americanos possui um investimento baixo na saúde. Em 2018, por exemplo, o gasto governamental em saúde situava-se em 2,2\% do PIB regional, abaixo dos $6 \%$ recomendados pela Organização Pan-Americana da Saúde (CEPAL, 2020a, p. 10). Outro

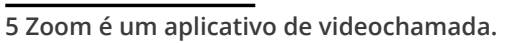

6 Entre essas startups pode-se citar a Netshow.me e agências como a Clap.me, conforme menciona o jornalista Leo Feijó (2020). 
aspecto ressaltado pela CEPAL é o vínculo informal. De acordo com a Organização Internacional do Trabalho (OIT), em 2016, 53,1\% dos trabalhadores da região estavam no setor informal (CEPAL, 2020a, p. 11). E, por fim, o aumento dos índices de pobreza e extrema pobreza. Segundo o estudo da CEPAL (2020b), em 2018, em torno de $30,1 \%$ da população regional estava abaixo da linha de pobreza e $10,7 \%$ estavam na extrema pobreza.

Esses aspectos são agravados pela pandemia e a CEPAL (2020c) projetou que a economia da região sofrerá uma redução de $7,7 \%$ em 2020, sendo a região mais afetada pela crise derivada da COVID-19 em relação aos países emergentes. Essa estimativa vem acompanhada de um aumento expressivo na taxa de desocupação, que deverá girar em torno de 10,7\% segundo o Balanço Preliminar das Economias da América Latina e do Caribe (2020c), publicado pela CEPAL em dezembro de 2020. A CEPAL (2020a) estimou que em 2020 a pobreza na América Latina aumentaria em pelo menos 4,4 pontos percentuais em relação ao ano anterior, atingindo um total de 214,7 milhões de pessoas ( $34,7 \%$ da população da região).

No Brasil, a perspectiva, segundo o estudo da CEPAL (2020c), é de queda de $5,3 \%$ no PIB para 2020. No que tange ao emprego, os dados do terceiro trimestre de 2020 (IBGE, 2020) apontam que a taxa de desocupação chegou a 14,6\%, correspondendo a 14,1 milhão de pessoas, sendo que a maior proporção é na região Nordeste (17,9\%). A pesquisa também apresentou dados para a diferença racial e de gênero na taxa de desocupação. De acordo com os dados, o percentual de desocupados para os homens foi de $12,8 \%$ e de $16,8 \%$ para as mulheres. Em relação à população preta, a taxa foi de $19,1 \%$, enquanto a dos pardos foi de $16,5 \%$, e a dos brancos ficou em $11,8 \%$.

Diante desse cenário, as ações governamentais ficaram aquém do esperado. Embora o Senado Federal tenha aprovado, em 20 de março, o decreto legislativo que reconheceu o estado de calamidade pública no Brasil em decorrência da pandemia do coronavírus (BRASIL, 2020a), o executivo federal adotou uma 
A pandemia da Covid-19 e seus impactos no setor cultural brasileiro

Mariana de Araujo Aguiar • Luciana de Araujo Aguiar

postura de negacionismo da doença, ignorando os protocolos da Organização Mundial da Saúde. As medidas de estabelecimento de quarentenas, de distanciamento social e uso de máscaras foram adotadas por governadores e prefeitos. Em pronunciamento no dia 24 de março, o presidente Bolsonaro criticou governadores por determinarem quarentena - com fechamento de comércio e barreiras sanitárias entre municípios - , questionou o motivo pelo qual escolas foram fechadas e criticou a imprensa (BOLSONARO..., 2020).

A atitude negacionista tem tido drásticas consequências, como: a instabilidade na gestão da saúde pública, o que acarretou a mudança de dois ministros da saúde durante o período da pandemia; ${ }^{7}$ o crescente número de casos confirmados e mortos, o que levou o Brasil a ser o segundo país com maior número absoluto de $\operatorname{casos}^{8}$ atrás apenas dos Estados Unidos (WHO, 2020); a demora em responder aos auxílios financeiros para pequenas e médias empresas e para a população de baixa renda.

No que tange a este último, a proposta inicial do governo era um voucher de $\mathrm{R} \$ 200,00$ aos trabalhadores informais (POMPEU, 2020), sendo esta ampliada pelo plenário através da PL 9.236/2017, aprovada pelo poder legislativo e sancionada pelo presidente no dia 2 de abril (BRASIL, 2020b). O auxílio emergencial de $\mathrm{R} \$ 600,00$ (em torno de $57,42 \%$ do salário mínimo vigente em 2020$)^{9}$ voltado para trabalhadores cuja renda familiar mensal per capita é de até 1/2 (meio) salário mínimo ou a renda familiar mensal total de até 3 (três) salários mínimos estava previsto, inicialmente, por três meses e foi prorrogado por mais dois. E, no dia 1 de setembro, o governo decidiu estender o auxílio até dezembro de 2020 com um valor de $\mathrm{R} \$ 300,00$, metade do valor inicial.

O negacionismo também refletiu nas reduzidas atuações do governo federal para o setor cultural. Estas se resumiram em ajustes de prazos para captação, execução e prestação de contas de

\footnotetext{
70 primeiro ministro, o médico Luiz Henrique Mandetta, deixou o cargo em 16 de abril e o segundo, Nelson Teich, em 15 de maio. Desde esta data, o Ministério é ocupado pelo General do Exército Brasileiro Eduardo Pazuello, que primeiro assumiu o cargo interinamente e, em 16 de setembro, tomou posse como ministro da saúde oficial.

8 Dados referentes a 1 de setembro de 2020. Cf.: https://covid19.who.int/table.

90 salário mínimo no ano de 2020 era de $\mathrm{R} \$ 1.045,00$.
} 
A pandemia da Covid-19 e seus impactos no setor cultural brasileiro Mariana de Araujo Aguiar • Luciana de Araujo Aguiar

projetos aprovados por leis de incentivo fiscal (BRASIL, 2020c); na minimização dos efeitos dos cancelamentos para o setor de turismo e setor de eventos (BRASIL, 2020d). Assim, o poder executivo respondeu, de forma limitada, às demandas do setor que buscavam incentivos para a continuidade de seus trabalhos por meio de editais, auxílios e outros, uma vez que o setor cultural foi um dos primeiros a serem paralisados, ${ }^{10} \mathrm{e}$, provavelmente, será um dos últimos a serem normalizados.

Cabe ressaltar que o setor cultural há algum tempo já sofre com perdas orçamentárias e uma baixa atuação do governo federal. Desde o primeiro governo Dilma (2011-2014), na gestão de Ana de Hollanda (2011-2012), houve uma descontinuidade das políticas, reflexo do baixo orçamento da pasta. Enquanto no governo Lula a média do orçamento para a cultura era em torno de 0,80\% do orçamento total da União, na gestão Dilma essa porcentagem reduziu para $0,13 \%$ (MIRANDA, 2014). No entanto, podemos ressaltar que o primeiro governo Dilma foi marcado por algumas ações importantes, como: a criação da Secretaria de Economia Criativa, em 2012; a instituição do Sistema Nacional de Cultura, em 2012; e a aprovação da Lei Cultura Viva, em 2014.

No segundo governo Dilma (2015-2016) houve uma redução ainda maior do orçamento para a cultura. De acordo com o estudo de João Brant (2018), o ministério perdeu, entre 2011 e 2015, 43\% do seu orçamento voltados às ações finalísticas e, em 2015, especificamente, o autor aponta que o contingenciamento da política de austeridade fiscal afetou $36 \%$ do orçamento para a cultura.

Esse aspecto se agravou no pós-golpe de 2016, quando as políticas públicas foram minguadas, principalmente após a aprovação da PEC do teto dos gastos, que resultou na Emenda Constitucional 95/2016. Esta estabeleceu limites para as despesas primárias. Assim, na prática, os gastos públicos foram limitados aos gastos do exercício anterior corrigidos pela inflação. Vale a pena destacar que esse teto não é limitado para o pagamento das dívidas públi-

$\overline{10 \text { Primeiros decretos }}$ de fechamento de estabelecimentos culturais foram editados por estados e municípios entre 12 e 19 de março. 
A pandemia da Covid-19 e seus impactos no setor cultural brasileiro

Mariana de Araujo Aguiar • Luciana de Araujo Aguiar

cas, o que nos possibilita observar os fundamentos fiscais defendidos no governo de Michel Temer (2016-2018). Assim, no âmbito da cultura, Brant (2018) ressalta que o orçamento discricionário do Ministério da Cultura, em 2017, era de R \$553,4 milhões, uma perda de 45\% em relação aos valores de 2014 .

A continuidade da Emenda 95 no atual governo de Jair Bolsonaro e a extinção do Ministério da Cultura indicam o baixo orçamento destinado à cultura. Segundo os dados do Portal da Transparência (CGU, 2020), em 2019, o programa orçamentário "Cultura: dimensão essencial do desenvolvimento" teve um orçamento de $\mathrm{R} \$ 218,3$ milhões. A execução do orçamento do Fundo Nacional de Cultura foi de $\mathrm{R} \$ 17,11$ milhões. ${ }^{11}$ Portanto, essa queda no orçamento da cultura tem forte impacto para os grupos sociais mais vulneráveis.

Em período de isolamento social, provocado pela pandemia da Covid-19, esse baixo orçamento se torna ainda mais problemático, já que a premência da pandemia evidenciou a vulnerabilidade do setor em relação à continuidade de suas ações, as desigualdades no acesso às fontes de financiamento cultural e as desigualdades no acesso às ferramentas virtuais. De acordo com o IBGE (2019):

\begin{abstract}
A desvantagem é maior para os grupos vulneráveis: população preta ou parda (15,3\%), crianças $(15,6 \%)$ e sem instrução ou fundamental incompleto (17,7\%). Entre as Unidades da Federação, as maiores proporções da população em municípios sem provedor de internet estavam no Piauí (51,3\%) e em Tocantins (42,3\%). (IBGE, 2019).
\end{abstract}

As desigualdades, expressas em relação ao acesso à internet e à virtualização da produção cultural, nos fazem refletir sobre o papel do Estado na promoção dos direitos culturais, imprescindíveis para a participação dos indivíduos na sociedade. Os direitos

\footnotetext{
11 Fundo de natureza contábil, instituído pela Lei 8.313/91, conhecida como Lei Rouanet. Esse fundo tem por “objetivo captar e destinar recursos para projetos culturais compatíveis com as finalidades do Pronac" (BRASIL, 1991) e visa, entre outros aspectos, estimular a distribuição regional equitativa de recursos, contribuir para a preservação e proteção do patrimônio cultural e histórico brasileiro e priorizar as áreas artísticas e culturais com menos possibilidade de desenvolvimento com recursos próprios.
} 
culturais são variados e podem ser expressos como: o direito à produção e fruição, direito de participação nas diretrizes culturais, direito à formação, direito ao pluralismo, direito à memória coletiva e ao acesso (CHAUÍ, 2008). No ordenamento jurídico brasileiro, a Constituição Federal de 1988 define que o Estado apoiará e incentivará a difusão das manifestações culturais e garantirá o pleno exercício do direito cultural e do acesso às fontes da cultura nacional (BRASIL, 1988).

No entanto, conforme destaca Bucci (2001), a exigibilidade do direito requer não apenas a previsão na norma, mas o estabelecimento da agenda política, a formulação de alternativas, a decisão e a implementação da política pública. A autora aponta que: “Há uma estreita relação entre os temas das políticas públicas e dos direitos humanos. Pois uma das características do movimento de ampliação do conteúdo jurídico da dignidade humana é a multiplicação das demandas por direitos" (BUCCl, 2001, p. 13). Nessa abordagem, a política pública tem como fundamento o cumprimento de direitos. Essa mesma visão está presente no artigo de Vázquez e Delaplace (2011). De acordo com os autores, a política pública na perspectiva dos direitos humanos deve considerar que o objetivo final da política seja o exercício do direito. Assim, segundo essa abordagem, os direitos humanos não devem estar isolados em um campo específico de política pública, mas devem ser um tema transversal a todas as políticas públicas.

O Estado brasileiro, no entanto, tem cada vez mais se eximido de sua responsabilidade jurídica de promoção dos direitos culturais, o que se evidencia no contexto pandêmico com as irrisórias ações promovidas pelo poder executivo federal. Para contornar essa situação, o poder legislativo assumiu um protagonismo na criação e implementação de política pública e garantia dos direitos culturais e de renda para os trabalhadores da cultura. A resposta para o setor cultural começou a ser debatida pela Câmara dos Deputados ainda em março, quando foi apresentado o projeto de lei 1075/2020, com o objetivo de estabelecer ações emergenciais destinadas ao setor cultural. 
O projeto tramitou na Câmara até ser aprovado no dia 26 de maio, seguindo para o Senado, que o aprovou no início de junho. Porém, a sanção do presidente só ocorreu no dia 29 de junho de 2020. A lei 14.017, denominada Lei Aldir Blanc, ${ }^{12}$ prevê o repasse de 3 bilhões de reais (cerca de 569 milhões de dólares), sendo $50 \%$ desse valor para estados e DF e 50\% para municípios (BRASIL, 2020e). A lei define as seguintes ações emergenciais: renda emergencial mensal de 3 parcelas de $R \$ 600,00$ reais aos trabalhadores e trabalhadoras da cultura; subsídio mensal de, no mínimo, R\$ 3.000,00 e, no máximo, $\mathrm{R} \$ 10.000,00$ para manutenção de espaços artísticos e culturais e micro e pequenas empresas; no mínimo, $20 \%$ do valor recebido pelo ente federado deverá ser destinado para editais, prêmios e chamadas públicas destinados à manutenção de agentes, de espaços, de iniciativas culturais.

A medida, apesar de importante, denota o quanto o processo legislativo é moroso em relação a uma ação mais enérgica do executivo. Cabe ressaltar que o legislativo, durante o período pandêmico, intensificou seu protagonismo, aprovando uma série de medidas que não foram propositivas pelo poder executivo. Esse aspecto evidencia um conflito entre os dois poderes que, segundo a análise de Almeida (2020), reflete tanto um fator conjuntural, na medida em que o presidente não possui uma posição majoritária no Congresso, mas também um fator estrutural que remete à mudança de padrão legislativo que vem ocorrendo desde 2008 no Brasil. No entanto, a inabilidade de negociação do atual governo é um dos aspectos que levam à exacerbação desse conflito.

Essa mesma inabilidade também foi analisada na coordenação federativa. O federalismo pós-Constituição Federal de 1988 foi baseado em um modelo compartilhado, combinando autonomia subnacional com coordenação nacional. Assim, coube à União a normatização e o financiamento de políticas com foco em sua expansão e no combate às desigualdades regionais (ABRUCIO et al., 2020). No entanto, desde a campanha eleitoral, o atual presidente tem contestado esse modelo. Com o slogan "Mais Brasil, Menos

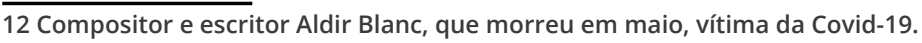


Brasília", Bolsonaro buscou implantar um federalismo dual, ou seja, autonomia dos entes federados, resultando em pouca atuação da União nas políticas públicas. Abrucio et al. (2020) ressaltam que a concentração autocrática de decisões que afetam as instâncias subnacionais reforça a posição do federalismo dual, na medida em que dificulta o diálogo e privilegia o confronto intergovernamental.

Essa postura dualista foi analisada nas ações de combate à Covid. A desarticulação federalista levou a um protagonismo dos estados frente à União e muitos deles promoveram arranjos de coordenação, como comitês, conselhos etc., com foco emergencial. O caso mais emblemático foi o Consórcio Nordeste, que reúne os estados da região Nordeste do país e articulou um Comitê Científico, com foco em fornecimento de informações para a tomada de decisão (LINHARES; RAMOS; MESSENBERG, 2020). Assim, apesar das ações dos estados, a descoordenação federativa tem efeitos perversos no aumento da desigualdade regional e, como apontam Abrucio et al. (2020), foi uma das causas para os péssimos resultados em relação ao número de doentes e mortos pela Covid.

\section{Percepções dos trabalhadores fluminenses da cultura sobre os impactos da pandemia}

A situação atualmente vivida pelo setor cultural nos levou a questionar sobre a percepção dos artistas tanto em relação à gestão governamental quanto sobre os impactos da pandemia em suas atividades. Para isso, elaboramos um questionário constituído de 31 perguntas, sendo 24 questões fechadas, 4 questões mistas e 3 questões abertas. Ele foi enviado por meio do aplicativo Google Forms, entre 15 de julho e 15 de agosto de 2020, a 106 trabalhadores fluminenses da cultura.

o questionário é um dispositivo padronizado que permite captar a presença ou ausência de determinadas características 
no indivíduo (SOUZA et al., 2005). O uso desse instrumento nos permite conhecer o perfil do informante, o impacto econômico e social da virtualização da cultura e do distanciamento social para esses respondentes e nos possibilita analisar, mesmo que de forma limitada, as percepções sobre a virtualização e a ação governamental para o setor cultural durante a pandemia. Como instrumento de coleta de dados, ele possui algumas vantagens, por exemplo, a não necessidade de deslocamento e contato físico, aspectos que seriam inviáveis no contexto da pandemia; confidencialidade e anonimato, o que possibilita que os respondentes fiquem mais livres para expor opiniões; e restringe a influência do pesquisador na opinião do respondente (GIL, 2008). No entanto, esse recurso apresenta algumas limitações, como, por exemplo, a exclusão de pessoas que não possuem acesso à internet e/ou domínio da plataforma utilizada, segrega aqueles que não sabem ler e escrever e "impede o conhecimento das circunstâncias em que foi respondido, o que pode ser importante na avaliação da qualidade das respostas" (GIL, 2008, p. 122).

A definição amostral da pesquisa ocorreu por conveniência e bola de neve, uma vez que, dado o contexto do isolamento social decorrente da pandemia, se buscou divulgar a pesquisa por meio de redes sociais, limitando, portanto, o alcance da pesquisa para o estado do Rio de Janeiro, ${ }^{13}$ principalmente para as cidades em que as pesquisadoras possuem mais contatos (Rio de Janeiro e Nova Friburgo). Portanto, a amostra não probabilística torna os resultados não generalizados, não garantindo a representatividade da população, além disso, pode limitar a variabilidade de narrativas, já que os respondentes foram indicados a partir das redes sociais das pesquisadoras e de terceiros.

No entanto, esse tipo de estudo é útil em pesquisas exploratórias, em processos que demandam pouco tempo para a coleta de dados e em situações em que não há conhecimento a respeito da amplitude da população pesquisada. No caso dos trabalhadores da cultura, apesar da existência do Sistema de Informações e

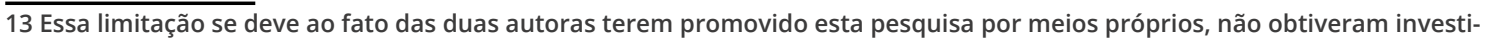
mento nem auxílio de outros pesquisadores. 
A pandemia da Covid-19 e seus impactos no setor cultural brasileiro

Mariana de Araujo Aguiar • Luciana de Araujo Aguiar

Indicadores Culturais, divulgado pelo IBGE (2019), que apresenta dados sobre trabalhadores da cultura por unidade da Federação e capitais dos estados, não há uma especificação para cada cidade, o que dificulta a identificação de probabilidade de seleção. Além disso, como apontam Sanchez e Nappo (2002 apud BALDIN; MUNHOZ, 2011), a escolha de sujeitos por meio da técnica bola de neve permite que os investigadores se aproximem da população investigada, o que é importante para um viés de análise qualitativo. Como o nosso enfoque é, também, captar a percepção dos trabalhadores da cultura sobre os impactos da pandemia em relação às ações governamentais e à virtualização da cultura, a escolha desse método foi estratégica, já que seria inviável a realização de entrevistas e outras técnicas por conta do isolamento social.

No que diz respeito aos métodos de análise dos dados, empregamos métodos mistos. A análise das perguntas fechadas foi realizada através de estatística descritiva básica disponibilizada pelo próprio aplicativo Google Formulário. Já as perguntas abertas foram examinadas a partir da análise discursiva, portanto, buscamos compreender as interpretações, os sentidos, os aspectos ideológicos e a retórica que, como destaca Gill (2003, p. 249), "dirige nossa atenção para as maneiras como todo discurso é organizado a fim de se tornar persuasivo".

A pesquisa foi respondida por mulheres e homens, majoritariamente entre 25 e 45 anos, e que habitam em zona urbana. No que se refere à atuação profissional, um pouco mais da metade dos entrevistados atua nos setores de música e teatro $(32,1 \%$ e $21,7 \%$, respectivamente). Os setores de artes visuais e audiovisual foram sinalizados como área de atuação por $23,6 \%$ dos entrevistados. ${ }^{14}$ Os outros campos artísticos mencionados no questionário, a saber: livro ou literatura; dança; circo; artesanato; turismo cultural; festivais e feiras; culturas populares e celebrações; conservação, restauração de bens materiais, concentram juntos $18,6 \%$ das respostas, com uma predominância dos setores de literatura e dança

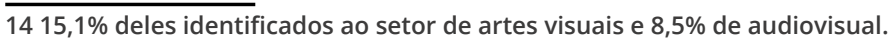


A pandemia da Covid-19 e seus impactos no setor cultural brasileiro

Mariana de Araujo Aguiar • Luciana de Araujo Aguiar

sobre os outros. ${ }^{15}$ Ainda sobre esse tema, indagamos a ocupação dos entrevistados. A maior parte dos artistas é de "autônomos informais" e microempreendedores individuais, respectivamente $41,5 \%$ e $21,1 \%$ dos entrevistados. ${ }^{16}$

Pareceu-nos pertinente, nesse contexto, indagar sobre o tipo de conexão à internet utilizada e a qualidade do acesso. As respostas do formulário nos permitem constatar que a maioria dos entrevistados $(58,5 \%)$ utiliza conexão via cabo e, em seguida, a 4 G (28,3\%). Em relação à qualidade do acesso, 79,2\% dos entrevistados a consideram "boa" ou "regular". Esses dados são importantes, uma vez que $76,4 \%$ dos entrevistados passaram a utilizar ferramentas online para a continuidade de suas atividades profissionais, ${ }^{17}$ o que somente $8,5 \%$ deles já faziam antes da pandemia.

De acordo com os resultados da pesquisa, 70\% dos entrevistados declararam ter acesso fácil a ferramentas gratuitas para exibição de seus trabalhos. Entre as ferramentas online mais utilizadas pelos interlocutores estão as redes sociais Instagram e Facebook e a plataforma de compartilhamento de vídeo YouTube, e apenas quatro entrevistados declararam usar a plataforma disponibilizada pelo setor público. No entanto, somente 7,9\% dos entrevistados conseguem monetizar seus serviços através dessas plataformas, uma vez que 50,8\% ainda não alcançaram o quantitativo de visualizações e de inscritos e 39,7\% não sabem como monetizar.

O uso das ferramentas online teve, entretanto, um impacto negativo na renda de uma grande parte dos entrevistados, já que $42 \%$ deles receberam menos com essa nova prática de atuação profissional e $21 \%$ deles tiveram mais gastos. ${ }^{18}$ Em relação a este último aspecto, as respostas nos mostraram que 57,8\% dos entrevistados precisaram comprar novos equipamentos para a continuidade da atividade profissional. Entre eles, podemos citar:

\footnotetext{
15 Quatro respostas assinalaram "outro" como setor de atuação, são eles: museu e comunicação. Duas respostas assinalaram que atuam em vários setores culturais.

16 10,4\% dos entrevistados são servidores públicos, 9,4\% prestadores de serviço e 6,6\% empregados CLT. $1750 \%$ deles começaram a utilizar parcialmente as ferramentas online, enquanto $26,4 \%$ totalmente.

18 Em relação a esta questão, $27,7 \%$ mencionaram que o uso das ferramentas online não impactou a renda, $12,3 \%$ teve menos gastos e $3,7 \%$ declarou que os recebimentos foram maiores.
} 
A pandemia da Covid-19 e seus impactos no setor cultural brasileiro

Mariana de Araujo Aguiar • Luciana de Araujo Aguiar

computador ou celular, softwares e equipamentos de áudio, vídeo ou de iluminação.

A virtualização da atividade artística/cultural durante a pandemia se tornou uma das questões-chave da nossa pesquisa e nos pareceu mais do que pertinente indagar sobre as vantagens e desvantagens dessa virtualização através de uma questão aberta. Entre as respostas que obtivemos, podemos apontar algumas vantagens que mais foram evidenciadas, como: o aumento da visibilidade, a ampliação da divulgação do trabalho, a criação de novas redes de contato, a economia de recursos e tempo devido ao não deslocamento, entre outras.

Em relação às desvantagens, duas delas foram bastante apontadas pelos respondentes: ausência da relação afetiva e tátil associada à falta de contato direto com o público e o excesso de trabalho, como apontou um informante: "Meu trabalho triplicou, hoje preciso saber gravar, editar, fazer arte gráfica, divulgar etc. E o dinheiro que ganho é pouco em relação à quantidade de funções que assumi" (Participante 39, questionário, 18 jul. 2020). ${ }^{19} \mathrm{~A}$ grande competição no território virtual, a baixa qualidade de áudio e vídeo do produto final e o pouco conhecimento dos recursos técnicos para o processo de virtualização são também citados como desvantagens nesse processo.

O distanciamento social causado pela pandemia atinge sobremaneira o setor cultural, visto que grande parte das produções se faz de maneira coletiva. De acordo com os dados do formulário, $54,7 \%$ dos respondentes declararam trabalhar de maneira coletiva. Entre os impactos do distanciamento citados pelos artistas estão: a dificuldade de comunicação com os integrantes dos grupos/ companhias em função da qualidade da conexão; desmotivação e falta de inspiração; estresse devido às constantes reuniões pelas plataformas; interrupção de ensaios presenciais; e diminuição da renda. Alguns artistas destacaram alguns aspectos positivos, como novas possibilidades de atuação através das câmeras do celular e computador e o estabelecimento de diálogos com outros coletivos.

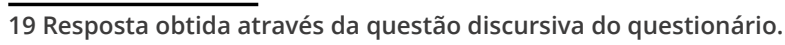


A pandemia da Covid-19 e seus impactos no setor cultural brasileiro

Mariana de Araujo Aguiar • Luciana de Araujo Aguiar

Além dos impactos gerados pelo distanciamento, indagamos igualmente sobre aquele gerado na renda mensal: $79,2 \%$ dos respondentes tiveram sua renda reduzida, sendo que para 39,6\% deles a renda reduziu mais de 50\%; para $22,6 \%$ reduziu menos de 50\%; e para 17\% reduziu cerca de 50\%. Estas informações se associam às dificuldades de continuidade do trabalho neste contexto, uma vez que para 39,6\% não há possibilidade de continuar o trabalho sem auxílio financeiro e para $44,3 \%$ deles é possível continuar parte do trabalho, porém com perdas de remuneração.

O trabalho no setor cultural corresponde à maior parte da renda (entre 75 e $100 \%$ da renda mensal) para 47,2\% dos informantes. E, com a pandemia, 26,4\% dos respondentes tiveram seus contratos de trabalho suspensos, 22,6\% tiveram redução salarial, $15,1 \%$ tiveram redução da carga horária e, quando questionados sobre outras medidas, alguns trabalhadores da cultura apontaram a paralisação de seu trabalho e adiamento de datas agendadas. Tendo em vista os dados citados, as políticas públicas de apoio para o setor se fazem necessárias para a continuidade das atividades culturais e artísticas no estado do Rio de Janeiro.

No que se refere ao auxílio emergencial, regulado pela Lei 13.982 , de 2 de abril de 2020, observamos que apenas $25,5 \%$ dos respondentes receberam o auxílio. Destes, $63 \%$ tiveram dificuldade em acessá-lo, o que indica algumas limitações na viabilidade do benefício. Um dos entrevistados ressaltou que recebeu apenas uma parcela do auxílio e, posteriormente, o aplicativo acusou "em avaliação", não permitindo receber as outras parcelas. De acordo com a reportagem de Marinho (2020), a cada novo pagamento da parcela é feita uma reanálise para que a Dataprev cheque se o cidadão ainda cumpre os requisitos para receber o auxílio. ${ }^{20}$ No entanto, a avaliação pode levar alguns meses, como ocorreu com o inquirido, resultando no prosseguimento ou cancelamento do benefício.

20 Dataprev é uma empresa pública que fornece soluções de informações para aprimoramento e execução de políticas sociais. Ela é a empresa responsável pelo processamento e cruzamento de informações autodeclaradas pelo cidadão no cadastro. 
A pandemia da Covid-19 e seus impactos no setor cultural brasileiro

Mariana de Araujo Aguiar • Luciana de Araujo Aguiar

No que tange aos programas emergenciais voltados para o setor cultural, indagamos sobre os editais no âmbito estadual e municipal. Observamos que a maior parte dos respondentes $(78,3 \%)$ não foi contemplada em nenhum edital até aquele momento; 10,4\% foram contemplados em edital estadual; 4,7\% em edital municipal; e 6,6\% em ambos. Em relação à Lei Aldir Blanc, observamos que 5,8\% não se consideravam informados sobre a lei; 51,9\% se consideravam parcialmente informados; e apenas 12,3\% dos entrevistados possuíam informações suficientes. Daqueles que se consideravam informados parcialmente ou totalmente, a maioria $(64,5 \%)$ apontou que adquiriu as informações por meio das redes sociais e por colegas de profissão (55,9\%). ${ }^{21}$ Quando questionados sobre os problemas de efetivação e implantação da lei, ${ }^{22}$ 54,4\% destacaram o reduzido diálogo entre os artistas e a Secretaria de Cultura; 50\% apontaram a ausência de procedimentos de gestão; e 48,5\% apontaram a ausência do cadastro do setor cultural.

Os dados apresentados acima nos permitem concluir a inabilidade das secretarias de Cultura, nos âmbitos federal, estadual e municipal, em tornar públicas as medidas necessárias para a implementação da lei, dificultando, assim, o acompanhamento pela sociedade civil. No entanto, é importante observar que a pesquisa foi realizada antes da publicação do decreto 10.464, de 17 de agosto de 2020, que regulamenta a lei. Portanto, a carência de informações veiculadas pelos órgãos oficiais das secretarias de Cultura pode estar associada à morosidade da publicação do decreto do poder executivo (um mês e 20 dias após a aprovação da Lei Aldir Blanc).

Além do auxílio financeiro e dos editais de fomento, questionamos sobre quais outras medidas o setor público poderia oferecer ao setor cultural: ${ }^{23}$ 58,5\% assinalaram a disponibilidade de plataforma direcionada ao cadastro de produtos e serviços culturais para vendas online; 41,5\% apontaram a formação nas

\footnotetext{
21 A pergunta permitia assinalar mais de uma opção. Portanto, a soma das porcentagens foi maior do que $100 \%$. Além das redes sociais e dos colegas de profissão, $29,4 \%$ se informaram por meio de jornais e revistas virtuais, $17,6 \%$ pelo conselho de cultura; 13,2\% por sites da prefeitura ou secretaria de Cultura do estado; e 5,9\% pelos jornais televisivos.

22 A pergunta também permitiu assinalar mais de uma opção.

23 A pergunta também possibilitou mais de uma opção.
} 
A pandemia da Covid-19 e seus impactos no setor cultural brasileiro

Mariana de Araujo Aguiar • Luciana de Araujo Aguiar

Novas Tecnologias da Informação e Comunicação (NTIC); e 39,6\% destacaram a formação de redes de pares/rede de indivíduos pertencentes à mesma atividade artística. ${ }^{24}$

Por fim, nos pareceu pertinente indagar a opinião a respeito das políticas culturais em período de pandemia. Entre as 106 respostas obtidas, a maioria apontou a carência de políticas públicas para a cultura não apenas no período da pandemia, mas nos últimos anos, como ressaltou um dos inquiridos: "Há tempos os profissionais da cultura vêm sofrendo com cortes, poucos editais, pouco ou nenhum auxílio do governo para o fomento da cultura e desvalorização dos artistas enquanto profissionais" (Participante 107, questionário, 14 ago. 2020). ${ }^{25}$

Além da carência e escassez de políticas públicas para a cultura, outros apontaram a inexistência de tais políticas, como explicitou um dos respondentes:

[...] Não há nenhuma política pública em andamento. Existem editais tapa-buracos, que replicam um modelo de modos de produção já falido [...]. O velho modelo, que exige dos proponentes a realização de um produto artístico em troca de um valor financeiro, não contempla o atual momento devido à própria especificidade da crise social e de saúde. (Participante 45, questionário, 18 jul. 2020). ${ }^{26}$

A visão do informante remete a um assunto que se revelou em outras respostas e que julgamos importante analisar: a crítica ao modelo de gestão baseado nos editais. Estes são mecanismos de seleção pública e se tornaram um importante meio de financiamento da cultura, tanto para acesso direto aos recursos públicos quanto para as leis de incentivo fiscal. Os argumentos para a adoção desse mecanismo apontam melhoria na distribuição regional de recursos e a transparência. Além disso, o edital é visto como um

\footnotetext{
24 Outras opções assinaladas foram: consultoria (34\%), formação em empreendedorismo e finanças (32,1\%), auxílio psicológico $(31,1 \%)$, informações sobre protocolos sanitários $(26,4 \%)$. Os inquiridos puderam escrever sobre outras opções e alguns assinalaram os editais, fóruns de estudo públicos para pensar as futuras ações para auxílio do setor etc.

25 Resposta obtida por meio da questão discursiva do questionário.

26 Resposta obtida por meio da questão discursiva do questionário.
} 
importante mecanismo democrático de seleção. Alguns autores, porém, criticam a preponderância dos editais, como Salgado et al. (2010), que ressaltam que esse meio não deve ser uma solução generalizada. Os autores afirmam que o edital é um instrumento burocrático e seu acesso não é igualitário devido à linguagem técnica e às exigências de seleção.

O trecho da resposta do Participante 45, citado acima, faz uma crítica ao modelo de edital que requer uma contrapartida, no entanto, outras críticas dos inquiridos nos pareceram mais próximas da análise de Salgado et al. (2010), como, por exemplo:

Apesar da implementação da Lei, muitos entraves são colocados
para se obter o benefício. Barreiras que circundam um problema
de gestão que já vem há anos sendo vivenciada no ambiente
cultural. Faltam de fato políticas que sustentem concretamente
e dêem garantia para os profissionais da área, durante e
posteriormente a pandemia. (Participante 55, questionário, 18
jul. 2020). ${ }^{27}$

\section{3}

Portanto, o foco da crítica é o modelo de gestão baseado em editais que apresenta barreiras para muitos artistas e que não possibilite uma sustentabilidade concreta do fazer artístico. Cabe apontar que os editais, no Brasil, seguem um modelo licitatório baseado na filosofia gerencial. Portanto, a adoção desse instrumento não é neutra, indica uma concepção de política pública e de democracia na qual a participação se expressa por meio de uma suposta igualdade na proposição de projetos. Assim, ao mesmo tempo em que esse modelo gera vantagens, gera também problemáticas, como: a lógica meritocrática, já que os critérios definidos em editais traduzem a necessidade de qualificação técnica para compreender sua lógica e a adequação do projeto às demandas dos editais; assim, esse modelo é inadequado aos agentes de cultura, principalmente àqueles que não possuem expertise de editais, entre outras.

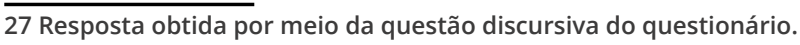


A pandemia da Covid-19 e seus impactos no setor cultural brasileiro

Mariana de Araujo Aguiar • Luciana de Araujo Aguiar

Outro aspecto levantado quanto ao modelo de editais refere-se à limitação quanto à sustentabilidade dos projetos culturais. Assim, para alguns, os editais são vistos como uma forma clientelista, como podemos observar na seguinte resposta de um dos entrevistados:

\begin{abstract}
Enquanto tínhamos editais acontecendo, havia dinheiro entrando para os agentes culturais. Acabando os editais, todo mundo ficou num estado de desespero. Se o dinheiro fosse investido em ações que estruturassem o setor cultural e permitissem autonomia de trabalho aos integrantes deste setor - em vez de uma política assistencialista que nos deixa dependentes do estado e/ou das empresas - possibilitando que o empreendedorismo no setor seguisse com suas próprias pernas - talvez estivéssemos melhores quando nos deparamos com situações de crise. (Participante 69, questionário, 18 jul. 2020). ${ }^{28}$
\end{abstract}

Portanto, podemos observar que a crítica realizada remete à ausência de ações que pudessem promover o empreendedorismo do setor cultural e a dependência do setor cultural aos editais. A sua crítica, no entanto, não veio acompanhada de proposições sobre o modelo de gestão. Outros inquiridos, porém, apresentam a importância de uma gestão democrática, como na seguinte resposta: "Quem é de cultura precisa ser inserido diretamente no contexto, opinar (...), afinal, o artista, de qual modalidade for, é o maior interessado em que verdadeiramente as decisões aconteçam para contemplar a todos de forma democrática e transparente" (Participante 78, questionário, 20 jul. 2020). ${ }^{29}$

Portanto, um assunto que sobressaiu nas análises e críticas realizadas pelos questionados foi o modelo de gestão pública. Outro tema que esteve presente em algumas falas foi a descontinuidade de algumas políticas no âmbito federal, como podemos observar na seguinte resposta:

28 Resposta obtida por meio do questionário. 29 Resposta obtida por meio do questionário. 
Já vivíamos uma crise no setor cultural em âmbito federal com a extinção do Minc, anteriormente à pandemia da Covid-19. Mas é uma vitória a aprovação de leis de auxílio emergencial para a cultura, tanto no Município quanto no Estado, que atendem de forma paliativa à classe artista. Porém, as leis de incentivo à cultura e manutenção da mesma precisam voltar às discussões a nível federal, no pós-pandemia. (Participante 88, questionário, 20 jul. 2020). ${ }^{30}$

Logo, podemos observar críticas ao governo federal no que tange à ausência do Ministério da Cultura e às descontinuidades das leis de incentivo. Outros respondentes também criticaram os governos estaduais e municipais, como se observa na seguinte fala: "A nível municipal não existe política pública cultural que contemple os artistas e o público. As poucas ações beneficiam apenas os 'apadrinhados', a nível federal e estadual o que acompanho é a tentativa de desmonte" (Participante 100, questionário, 24 jul. 2020).

\section{5}

Por fim, apesar de críticas diretas aos atuais governos nos âmbitos federal, estadual e municipal, os questionados ressaltaram a escassez de políticas, suas insuficiências e, principalmente, suas ineficiências no que tange ao alcance do público-alvo, à burocratização, à ausência de gestão democrática e de ações estruturantes e não apenas conjunturais. Portanto, o aspecto que se tornou mais evidente refere-se ao modelo de gestão e suas ineficiências.

\section{Considerações finais}

A pandemia da Covid-19 tem impactado de maneira colossal economias, relações interpessoais, hábitos, sistemas educacionais ao redor do mundo. No que se refere ao setor cultural, este impacto adquire proporções ainda maiores com a interrupção de

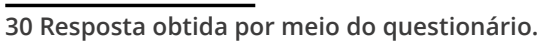


atividades artísticas e culturais e a avalanche de cancelamentos de festivais e eventos ligados à economia criativa. $\mathrm{O}$ isolamento social devido à pandemia não só modificou as formas de produção e consumo dos diversos elementos culturais e artísticos, mas impactou de maneira profunda a economia do setor.

Em nossa pesquisa, verificamos que grande parte dos entrevistados $(76,4 \%)$ passou a utilizar ferramentas online para a continuidade das suas atividades profissionais, o que somente $8,5 \%$ deles já faziam antes da pandemia. No entanto, a maioria $(90,5 \%)$ não consegue monetizar suas obras na internet e, além disso, 42\% deles receberam menos com a virtualização da atividade artística e $21 \%$ tiveram mais gastos com compras de equipamentos, planos de internet e outros. Portanto, apesar de alguns benefícios apontados, as desvantagens vão além do fator econômico e abarcam ausência da relação afetiva e tátil associada à falta de contato direto com o público e o excesso de trabalho.

A virtualização também se torna preocupante no que tange às desigualdades de acesso à internet. Os dados do IBGE (2019) apontam que cerca de $30 \%$ da população brasileira não teve acesso à internet em 2017, no entanto, grande parte dos usuários utiliza o celular e as conexões 3G/4G, o que configura em uma internet de dados limitados, prejudicando o acesso e a produção cultural de uma parte considerável da população brasileira.

Dado esse contexto, se tornou importante analisar as ações governamentais para o setor cultural em período de pandemia. No Brasil, a desarticulação federalista, como ressaltou Abrucio et al. (2020), e o protagonismo do legislativo, como apontou Almeida (2020), também são evidentes no campo da cultura. Enquanto a Secretaria Especial de Cultura não promoveu nenhuma ação efetiva no combate aos impactos da Covid-19, observamos diversas ações sendo realizadas em estados e municípios. O portal da Confederação Nacional de Municípios (CNM) realizou um mapeamento de ações de estados para reduzir os impactos negativos da pandemia no setor cultural. O levantamento da CNM (2020), publicado no dia 25 de março e atualizado no dia 8 de abril, res- 
salta uma série de editais que foram divulgados nos estados da federação. Essas ações, no entanto, não foram vinculadas a uma política pública federal coordenada. Além disso, expressam uma reduzida preocupação do gestor federal em relação aos repasses de verba, já que a União tem maior capacidade financeira e política para gerir políticas públicas de forma mais equânime.

Quando questionamos, em nossa pesquisa, sobre a opinião a respeito das políticas públicas, verificamos que alguns assinalaram as ações realizadas por municípios e estados. No entanto, o aspecto que mais se evidenciou nas respostas foram os problemas de gestão, tanto a respeito dos editais quanto a respeito da ausência de gestão democrática. Portanto, o que nos pareceu evidente é a contestação do modo de política cultural exercida no Brasil, que, além de insuficiente, apresenta ineficiências. Assim, algumas respostas ressaltaram o desmonte no âmbito federal, que resultou nas reduzidas ações emergenciais para a cultura.

\section{7}

\section{Referências}

ABRUCIO, Fernando Luiz et al. Combate à COVID-19 sob o federalismo bolsonarista: um caso de descoordenação intergovernamental. Revista de Administração Pública, Rio de Janeiro, n. 54, v. 4, p. 663-677, 2020.

AGRELA, Lucas; CURY, Maria Eduarda; VITORIO, Tamires. Na quarentena, o mundo virou uma live. Exame, [s.l.], 23 abr. 2020. Disponível em: https://exame.com/revista-exame/o-mundo-euma-live/. Acesso em: 20 jun. 2020.

ALMEIDA, Acir. Relações executivo-legislativo e governabilidade à luz da crise da Covid-19. In: INSTITUTO DE PESQUISA ECONÔMICA APLICADA [IPEA]. Nota Técnica da Diretoria de Estudos e Políticas do Estado, das Instituições e da Democracia Brasília: IPEA, n. 34, abr. 2020. 
BALDIN, Nelma; MUNHOZ, Elzira M. Bagatin. Snowball (bola de neve): uma técnica metodológica para pesquisa em educação ambiental comunitária. In: CONGRESSO NACIONAL DE EDUCAÇÃO, 10, Curitiba. Anais [...]. Curitiba: Pontífica Universidade Católica do Paraná, 2011. Disponível em: https://educere.bruc.com.br/ CD2011/pdf/4398_2342.pdf. Acesso em: 6 jan. 2021.

BOLSONARO critica imprensa e fechamento de escolas e diz que crise passará. UOL Notícias, São Paulo, 24 mar. 2020. Disponível em: https://noticias.uol.com.br/politica/ultimas-noticias/2020/03/24/covid-19-bolsonaro-culpa-imprensa-por-panicoe-volta-a-falar-gripezinha.htm. Acesso em: 18 abr. 2020.

BRANT, João. A morte lenta das políticas federais de cultura. In: ROSSI, Pedro; DWECK, Esther; OLIVEIRA, Ana Luíza Matos de.

Economia para poucos: impactos sociais da austeridade e alternativas para o Brasil. São Paulo: Autonomia Literária, 2018. p. 171-188.

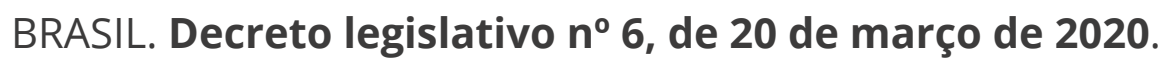

\section{8} Reconhece, para os fins do art. 65 da Lei Complementar $n^{\circ}$ 101, de 4 de maio de 2000, a ocorrência do estado de calamidade pública [...]. Brasília: Senado Federal, 2020a. Disponível em: https://www.in.gov.br/en/web/dou/-/decreto-legislativo-249090982. Acesso em: 21 maio 2020.

BRASII. Lei $\mathbf{n}^{\circ} \mathbf{1 3 . 9 8 2}$, de 2 de abril de 2020. Altera a Lei ${ }^{\circ}$ 8.742, de 7 de dezembro de 1993, para dispor sobre parâmetros adicionais de caracterização da situação de vulnerabilidade social [...] Brasília: Congresso Nacional, 2020b. Disponível em: https://www.in.gov.br/en/web/dou/-/lei-n-13.982-de-2-de-abrilde-2020-250915958. Acesso em: 28 maio 2020.

BRASIL Ministério da Cidadania. Instrução normativa $\mathbf{n}^{\circ} \mathbf{5}$, de 20 de abril de 2020. Estabelece procedimentos extraordinários para captação, execução, prestação de contas e avaliação de resultados de projetos culturais financiados por meio do mecanismo incentivo a projetos culturais do Programa Nacional de Apoio 
à Cultura (Pronac) em razão da Covid-19 e em face das diretrizes fixadas pela União, estados, municípios e Distrito Federal. Brasília: Ministério da Cidadania, 2020c. Disponível em: https:// www.in.gov.br/web/dou/-/instrucao-normativa-n-5-de-20-deabril-de-2020-253341026. Acesso em: 30 maio 2020.

\section{BRASIL. Medida provisória n 948, de 8 de abril de 2020.}

Dispõe sobre o cancelamento de serviços, de reservas e de eventos dos setores de turismo e cultura em razão do estado de calamidade pública reconhecido pelo Decreto Legislativo $n^{\circ} 6$, de 20 de março de 2020, e da emergência de saúde pública de importância internacional decorrente do coronavírus (Covid-19). Brasília, DF, 2020d. Disponível em: https://www.in.gov.br/en/web/ dou/-/medida-provisoria-n-948-de-8-de-abril-de-2020-251768019. Acesso em: 25 maio 2020.

BRASIL. Lei $\mathbf{n}^{\circ} \mathbf{1 4 . 0 1 7}$, de 29 de junho 2020. Dispõe sobre ações emergenciais destinadas ao setor cultural a serem adotadas durante o estado de calamidade pública reconhecido pelo Decreto Legislativo $\mathrm{n}^{\circ}$ 6, de 20 de março de 2020. Brasília: Congresso Nacional, 2020e. Disponível em: http://www.planalto.gov.br/ ccivil_03/_ato2019-2022/2020/lei/L14017.html. Acesso em: 15 jul. 2020.

\section{BRASIL. [Constituição (1988)] Constituição da República}

Federativa do Brasil de 1988. Brasília, DF: Presidência da República, 1988. Disponível em: http://www.planalto.gov.br/ccivil_03/Constituicao/Constituicao.htm. Acesso em: 18 jan. 2021.

BRASIL. Lei $n^{\circ}$ 8.313, de 23 de dezembro de 1991. Restabelece princípios da Lei $n^{\circ} 7.505$, de 2 de julho de 1986, institui o Programa Nacional de Apoio à Cultura (Pronac) e dá outras providências. Brasília: Congresso Nacional, 1991. Disponível em: http://www.planalto.gov.br/ccivil_03/leis/18313cons.html. Acesso em: 18 jan. 2021.

BRÊDA, Lucas. Superproduzidas, lives dos sertanejos lucram e causam polêmica na pandemia. Folha de São Paulo, São 
Paulo, 8 abr. 2020. Disponível em: https://www1.folha.uol.com. br/ilustrada/2020/04/superproduzidas-lives-dos-sertanejos-lucram-e-causam-polemica-na-pandemia.shtml. Acesso em: 18 abr. 2020.

BUCCI, Maria Paula Dallari. Buscando um Conceito de Políticas Públicas para a Concretização dos Direitos Humanos. In: $\mathrm{BUCCl}$, Maria Paula Dallari et al. Direitos humanos e políticas públicas. São Paulo: Instituto Pólis, 2001 - (Cadernos Pólis; 2). p. 5-16.

CEPAL. América Latina y el Caribe ante la pandemia del COVID-19: Efectos económicos y sociales. Informe Especial covid-19, n.1, [s.l.], CEPAL 2020a. Disponível em : https://repositorio.cepal.org/ bitstream/handle/11362/45337/6/S2000264_es.pdf. Acesso em: 25 jul. 2020.

CEPAL. Panorama Social da América Latina, 2019. Resumo executivo. Santiago: CEPAL, 2020b. Disponível em: https://repositorio.cepal.org/bitstream/handle/11362/45090/1/S1900909_pt.pdf. Acesso em: 5 ago. 2020.

CEPAL. Balance Preliminar de las Economías de América Latina y el Caribe, 2020. Santiago: CEPAL, 2020c.

CHAUI, Marilena. Cultura e democracia: Crítica y emancipación. Revista latinoamericana de Ciencias Sociales, Buenos Aires, ano 1, n. 1, p. 53-76, jun. 2008.

CONFEDERAÇÃO NACIONAL DE MUNICÍPIOS [CNM]. CNM faz mapeamento das medidas estaduais para enfrentar os impactos do coronavírus no setor cultural. Brasília, 25 mar 2020. Disponível em: https://www.cnm.org.br/comunicacao/noticias/ cnm-faz-mapeamento-das-medidas-para-enfrentar-os-impactos-do-coronavirus-no-setor-cultural. Acesso em: 18 maio 2020.

CONTROLADORIA GERAL DA UNIÃO [CGU]. Portal da Transparência do Governo federal, Fundo Nacional de Cultura; Secretaria Especial de Cultura: Banco de dados. Disponível em: http://www.portaltransparencia.gov.br . Acesso em:16 dez. 2020. 
FEIJÓ, Leo. Coronavírus: como monetizar sua 'live' musical. União Brasileira de Compositores, Rio de Janeiro, 30 mar. 2020.

Disponível em: http://www.ubc.org.br/Publicacoes/Noticias/15122 Acesso em: 15 maio 2020.

GIL, Antonio Carlos. Métodos e Técnicas de pesquisa social. 6 ed. São Paulo: Atlas, 2008.

GILL, Rosalind. Análise do discurso. In: BAUER, Martin W.; GASKELL, George (org.). Pesquisa qualitativa com texto, imagem e som: um manual prático. 2 ed. Petrópolis:Vozes, 2003. p. 244-270.

HARVEY, David. Política anticapitalista em tempos de Covid-19. In: DAVIS, Mike et al. Coronavírus e a luta de classes. Terra sem Amos: Brasil, 2020. p. 13-23.

INSTITUTO BRASILEIRO DE GEOGRAFIA E ESTATÍSTICA (IBGE). Sistema de informações e indicadores culturais: 2007-2018. Rio de Janeiro, IBGE, 2019.

LATOUR, Bruno. Imaginar gestos que barrem o retorno da produção pré-crise. Tradução: Deborah Danowski e Eduardo Viveiros de Castro. AOC-Media, 29 mar. 2020. Disponível em: https://www.n-1 edicoes.org/textos/28. Acesso: 10 abr. 2020.

LESSING, Lawrence. Remix: Making Art and Commerce Thrive in the Hybrid Economy. New York: Penguin Books, 2009.

LÉVY, Pierre. Cibercultura. São Paulo: Editora 34, 1999.

LÉVY, Pierre. O que é virtual? São Paulo: Editora 34, 1996.

LINHARES, Paulo de Tarso Frazão Soares; RAMOS, Tarcila Queiroz; MESSENBERG, Roberto Pires. Inovação institucional na coordenação federativa para enfrentamento e saída do surto de covid-19 In: INSTITUTO DE PESQUISA ECONÔMICA APLICADA [IPEA]. Nota Técnica da Diretoria de Estudos e Políticas do Estado, das Instituições e da Democracia, n. 41, jul. 2020, Brasília: IPEA, 2020. p. 7-15. 
LOPES, Ana Maria D'Ávila. Proteção constitucional dos direitos fundamentais culturais das minorias sob a perspectiva do multiculturalismo. Revista de Informação Legislativa, Brasília, ano 45, n. 177, p. 19-29, jan./mar. 2008.

MARINHO, Natália. O que significa cadastro "em avaliação" no auxílio de $\mathrm{R} \$ 600$. Notícias concurso, [s.I.], 18 jun. 2020. Disponível em: https://noticiasconcursos.com.br/direitos-trabalhador/o-que-significa-cadastro-em-avaliacao-no-auxilio-de-r-600/. Acesso em: 16 set. 2020.

MIRANDA, André. O que marcou, positiva e negativamente, a gestão de Marta Suplicy à frente do MinC. $\mathbf{O}$ Globo, Rio de Janeiro, 12 nov. 2014. Disponível em: http://oglobo.globo.com/ cultura/o-que-marcou-positiva-negativamente-gestao-de-marta-suplicy-frente-do-minc-14533504\#ixzz4ETkMQJvF. Acesso em: 14 maio 2016.

POMPEU, Lauriberto. Guedes anuncia voucher de $\mathrm{R} \$ 200$ para trabalhador informal. Congresso em foco, Brasília, 18 mar 2020. Disponível: https://congressoemfoco.uol.com.br/governo/guedesanuncia-voucher-de-r-200-para-trabalhador-informal/. Acesso em: 24 jul. 2020.

RAMOS, Guilherme. Festivais online fazem sucesso na quarentena; saiba assistir aos shows. TechTudo, [s.l], 20 abr. 2020. Disponível em: https://www.techtudo.com.br/listas/2020/03/ festivais-online-fazem-sucesso-na-quarentena-saiba-assistir-aosshows.ghtml. Acesso em: 22 abr. 2020.

RÜDIGER, Francisco. A reflexão teórica em cibercultura e a atualidade da polêmica sobre a cultura de massas. Matrizes, São Paulo, v. 5, n. 1, p. 45-61, jul.-dez. 2011.

SALGADO, Gabriel Melo et al. As políticas de financiamento à cultura: a urgência de uma reforma. In: RUBIM, Antonio Albino Canelas. Políticas culturais no governo Lula. Salvador: Edufba, 2010. p. 87-122. 
A pandemia da Covid-19 e seus impactos no setor cultural brasileiro

Mariana de Araujo Aguiar • Luciana de Araujo Aguiar

SANTOS, Boaventura de Sousa. A cruel pedagogia do vírus.

Coimbra: Almedina, 2020.

SOUZA, Edinilsa Ramos de et al. Construção de instrumentos qualitativos e quantitativos. In: MINAYO, Maria Cecília de Souza; ASSIS, Simone Gonçalves; SOUZA, Edinilsa Ramos de. (org.). Avaliação por triangulação de métodos: abordagens de programas sociais. Rio de Janeiro: Fiocruz, 2005. p. 133-156.

VAZQUEZ, Daniel; DELAPLACE, Domitille. Políticas públicas na perspectiva dos direitos humanos: um campo em construção. SURRevista Internacional de Direitos Humanos, São Paulo, v. 8, n. 14, p. 35-65, jun. 2011.

WORLD HEALTH ORGANIZATION [WHO]. WHO Coronavirus Disease (COVID-19). Dashboard. Disponível em: https://covid19. who.int/. Acesso em: 21 ago. 2020. 